\title{
Formulation, development and characterization of mucoadhesive film for treatment of vaginal candidiasis
}

\author{
Renuka Mishra, Priyanka Joshi, Tejal Mehta \\ Department of Pharmaceutics and Pharmaceutical Technology, Institute of Pharmacy, Nirma University, Ahmedabad, Gujarat, India
}

\begin{abstract}
Objective: The objective of the present investigation was formulation, optimization and characterization of mucoadhesive film of clotrimazole (CT) which is patient-convenient and provides an effective alternative for the treatment of vaginal candidiasis. CT is an antimycotic drug applied locally for the treatment of vaginal candidiasis. Materials and Methods: Mucoadhesive vaginal films were prepared by solvent casting technique using hydroxyl propylcellulose and sodium alginate as polymers. Propylene glycol and polyethylene glycol-400 were evaluated as plasticizers. The mucoadhesive vaginal films were evaluated for percentage elongation, tensile strength, folding endurance, drug content, in vitro disintegration time, in vitro dissolution study, swelling index, bioadhesive strength, and diffusion study. Results: Among various permeation enhancers used, isopropyl myristate was found to be suitable. To evaluate the role of the concentration of permeation enhancer and concentration of polymers in the optimization of mucoadhesive vaginal film, $3^{2}$ full factorial design was employed. Optimized batch showed in vitro disintegration time, 18 min; drug content, $99.83 \%$; and tensile strength, $502.1 \mathrm{~g} / \mathrm{mm}^{2}$. In vitro diffusion study showed that $77 \%$ drug diffusion occurred in $6 \mathrm{~h}$. This batch was further evaluated by scanning electron microscopy indicating uniformity of the film. In vitro Lactobacillus inhibition and in vitro antifungal activity of optimized batch showed an inhibitory effect against Candida albicans and no effect on Lactobacillus, which is a normal component of vaginal flora. Conclusion: Mucoadhesive vaginal film of CT is an effective dosage form for the treatment of vaginal candidiasis.
\end{abstract}

Key words: Clotrimazole, hydroxypropyl cellulose, mucoadhesive film, sodium alginate, vaginal candidiasis

\section{INTRODUCTION}

Any condition causing an inflammation of the vagina is generally referred to as vaginitis, one of the most frequent gynecological diseases. Candidiasis and bacterial vaginosis are the two most common causes of vaginitis. Vaginal candidiasis (VC) is one of the prominent reasons for women requiring visit to a gynecologist. As per the literature, almost $75 \%$ of all adult women population have at least one genital recurrent yeast infection in their lifetime. It is also important to note that at least $50 \%$ of these women

\section{Address for correspondence:}

Dr. Renuka Mishra,

Institute of Pharmacy, Nirma University,

Ahmedabad - 382 481, Gujarat, India.

E-mail: renukasharma81@rediffmail.com

\begin{tabular}{|l|l|}
\hline \multicolumn{2}{|c|}{ Access this article online } \\
\hline Quick Response Code: & Website: \\
\hline & www.jpionline.org \\
\cline { 2 - 2 } & DOI: \\
\hline
\end{tabular}

experience, one or more recurrent episodes of VC in the future. Genus Candida, a type of yeast is pathogenic in human beings. Candida albicans is responsible for $90 \%$ vaginal fungal infection cases along with other Candida species, such as Candida glabrata and Candida parapsilosis. The increasing incidence of VC requires the need of an appropriate drug delivery approach for successful eradication of infectious agent, achieving higher drug levels at the site, avoidance of first-pass metabolism, a shorter regimen of therapy along with convenience and safety. The vaginal mucosa provides advantages such as large surface area, rich blood supply, and reduced side effects. Thus, vaginal drug delivery acts as

This is an open access article distributed under the terms of the Creative Commons Attribution-NonCommercial-ShareAlike 3.0 License, which allows others to remix, tweak, and build upon the work non-commercially, as long as the author is credited and the new creations are licensed under the identical terms.

For reprints contact: reprints@medknow.com

How to cite this article: Mishra R, Joshi P, Mehta T. Formulation, development and characterization of mucoadhesive film for treatment of vaginal candidiasis. Int J Pharma Investig 2016;6: 47-55. 
a potential site for local and systemic therapy. Conventional vaginal dosage forms such as creams, foams, pessaries, and jellies have short residence time at the site of application resulting in reduced therapeutic effect. Vaginal film is more preferred over gels by women due to its high patient compliance and leakage chances are very less after insertion. In addition, vaginal film possesses several advantages such as ease of storage and handling, no need of the applicator, and better stability of drug at the tropical condition. ${ }^{[1-5]}$ Clotrimazole (CT) is an imidazole derivative antimycotic drug used for the treatment of vaginal yeast infections. The objective of this investigation was to develop a mucoadhesive film of CT for the treatment of VC using the solvent casting method. Water soluble film forming polymers such as hydroxypropyl cellulose (HPC) and sodium alginate were selected. Propylene glycol (PG) and polyethylene glycol-400 (PEG-400) were selected as plasticizer. ${ }^{[6,7]}$ The mucoadhesive vaginal films were evaluated for percentage elongation, tensile strength, folding endurance, drug content, in vitro disintegration time, in vitro dissolution study, percentage swelling index, bioadhesive strength, in vitro diffusion study, ex vivo diffusion study, and in vitro antifungal activity.

\section{MATERIALS AND METHODS}

\section{Materials}

CT was purchased from Balaji Drug House, Surat, India. HPC was received as a gift sample from Gangawal Chemicals Pvt. Ltd., Mumbai, India. Sodium alginate was purchased from Finar Chemicals Ltd., Ahmedabad, India. PEG-400, PG and dimethyl sulfoxide (DMSO) were purchased from the Central Drug House Pvt. Ltd., New Delhi, India. Isopropyl myristate (IPM) was purchased from High Purity Laboratory Chemicals, Mumbai, India. All other chemicals used were of the analytical grade. Distilled water was used throughout the study.

\section{Methods}

\section{Drug-excipient compatibility study}

Compatibility studies were performed using Fourier transform infrared spectroscope (FTIR) (Jasco FTIR 6100 Type-A, Japan) and differential scanning calorimetry (DSC) (Shimadzu Corporation DSC-60, Japan). The FTIR spectra of the pure drug and physical mixture of drug: Polymers (1:2 ratio) were studied by using a KBr disc. Drug-excipient compatibility studies were conducted with the objective of selecting the compatible ingredients for mucoadhesive film. Any kind of incompatibility between CT and the film-forming polymer will affect its property to a significant extent.

\section{Preparation of films}

Films were prepared by the solvent casting method on suitable Teflon casting surface. Aqueous solution was prepared by dissolving HPC, sodium alginate and PG in $20 \mathrm{~mL}$ distilled water using a magnetic stirrer (Remi instruments, 2MLH, Mumbai) at $400 \mathrm{rpm}$ at room temperature. CT was added to the polymeric solution by continuous stirring at $400 \mathrm{rpm}$. The solution was then poured into a Petri dish followed by drying in a hot air oven (Erection Instruments and Engineers, 101, Ahmedabad) at $40^{\circ} \mathrm{C}$. After drying, the films were removed from the Petri dish and placed on a butter paper backing. The films were cut in $3 \mathrm{~cm} \times 3 \mathrm{~cm}$ dimensions using a sharp scalpel. The films were packed by carefully wrapping in an aluminum foil and stored at $37^{\circ} \mathrm{C}$ until further use. Peelability of films indicates the ease of removal of film from the casting surface. ${ }^{[8,9]}$

\section{Evaluation parameters of mucoadhesive film}

Thickness

The thickness of the films was measured by a Thermonik Tablet Tester (Campbell Electronics, DTH-250, Mumbai, India). Films were tested from three different positions by keeping the film in between two jaws of the machine, and the average thickness was calculated. ${ }^{[9]}$

\section{Percentage elongation}

This parameter indicates the elastic nature of the film. A digital tensiometer (Erection Instruments and Engineering, SE-2000, Ahmedabad, India) was used to calculate the percentage elongation of the film. Elongation was measured, when films break. ${ }^{[8,10]}$ Percentage elongation was calculated using the following equation (1):

Percentage elongation $=\frac{\text { Increase in length }}{\text { Original length }} \times 100$

Tensile strength

The mechanical properties of films were evaluated using a QTS texture analyzer (Brookfield Engineering Laboratories, QTS 25, Mumbai, India). ${ }^{[8,10,11]}$ The peak load was evaluated with the help of a dual grip jig probe. The QTS texture analyzer recorded the data when the probe started withdrawing from the film. The peak load and the area under load distance curve obtained from the texture profile were used to assess the tensile strength and percentage elongation of the films. Each measurement was repeated 3 times. Tensile strength was calculated using equation (2):

Tensile strength $=$

$$
\frac{\text { Force at break }(\mathrm{N})}{\text { Initial cross }- \text { sectional area of the film }\left(\mathrm{cm}^{2}\right)}
$$

\section{Folding endurance}

Folding endurance was determined by repeated folding of the film at the same place till it broke. The number of times the film can be folded without breaking was considered as folding endurance. ${ }^{[10,12]}$

Drug content

A $3 \mathrm{~cm} \times 3 \mathrm{~cm}$ film was dissolved in $5 \mathrm{~mL}$ of distilled water. $25 \mathrm{~mL}$ of methanol was added to the solution and filtered through whatman filter paper. The samples were assayed at $261 \mathrm{~nm}$ wavelength using a ultraviolet (UV)-visible spectrophotometer (Shimadzu Corporation UV 1800, Japan). The determinations were carried out in triplicate and an average of three readings was taken. . $^{[1,10,12-14]}$ 


\section{In vitro dissolution studies}

The in vitro dissolution studies of the optimized film were carried out using 500 simulated vaginal fluid (SVF) containing $5 \% \mathrm{w} / \mathrm{v}$ Tween 80 as a surfactant at $50 \mathrm{rpm}$ using the USP Type II dissolution apparatus (Electrolab TDT-08L, Mumbai, India) at $37 \pm 0.5^{\circ} \mathrm{C}$. CT is poorly soluble in water as well as SVF. For the correct estimation of drug, $5 \% \mathrm{w} / \mathrm{v}$ Tween 80 was added as a surfactant to dissolution media. The $5 \mathrm{~mL}$ sample was withdrawn at predetermined time intervals and fresh medium was used to replace the sample volume. The samples were filtered through $0.45 \mu \mathrm{m}$ membrane filter, diluted suitably and analyzed using a UV-visible spectrophotometer at $261 \mathrm{~nm}$ by blank correction method using SVF containing 5\% w/v Tween-80. Dissolution of each batch was repeated three times and the mean of all determinations was used to calculate the drug release profile from the equation generated by the standard curve estimation technique. ${ }^{[12,15]}$

\section{In vitro disintegration studies}

The disintegration time was determined by a modified disintegration method. A glass Petri dish $(6.5 \mathrm{~cm}$ diameter $)$ was filled with $10 \mathrm{~mL}$ of distilled water and the film was carefully placed at the center. The Petri dish was left undisturbed. The time for the film to completely disintegrate into fine particles was noted. The test was performed four times for each batch and the mean value was reported. ${ }^{[13,16]}$

\section{Swelling study}

Films of $3 \mathrm{~cm} \times 3 \mathrm{~cm}$ sizes were cut and weighed. The samples were allowed to swell on the surface of an agar plate kept in a biological oxygen demand incubator (M. Shah Trading Company, BLS-28, Vadodara) maintained at $37 \pm 0.2^{\circ} \mathrm{C}$. The increase in the weight of the films $(n=3)$ was determined at time intervals of $1-6$ h. $^{[9,10,12]}$

The percentage swelling index was calculated using the following equation:

Percentage swelling index $(\% \mathrm{~S})=\frac{\mathrm{W}_{\mathrm{t}}-\mathrm{W}_{0}}{\mathrm{~W}_{0}} \times 100$

where $\mathrm{W}_{\mathrm{t}}$ is the weight of the swollen film after time $\mathrm{t}, \mathrm{W}_{0}$ is the weight of film at zero time.

\section{Moisture content}

For the determination of moisture content, $3 \mathrm{~cm} \times 3 \mathrm{~cm}$ piece of film was weighed and kept in a desiccator containing calcium chloride at $40^{\circ} \mathrm{C}$ for $24 \mathrm{~h}$. Films were removed from the desiccator and weighed until a constant weight was obtained. The percentage of the moisture content was calculated as the difference between initial and final weights with respect to the initial weight. ${ }^{[10]}$

\section{In vitro drug diffusion study}

Drug diffusion is an important parameter for the mucoadhesive dosage form. As mucoadhesive film has to diffuse through the mucosal surface, in vitro diffusion study is required to estimate the amount of drug diffusion across the mucosa. A multi unit diffusion cell apparatus (Orchid Scientific, Mumbai, India) was used to check the percentage of the drug diffused from the film. Films of $3 \mathrm{~cm} \times 3 \mathrm{~cm}$ were dissolved in $5 \mathrm{~mL}$ of distilled water and $25 \mathrm{~mL}$ of methanol was dded to it. As HPC and sodium alginate are water soluble polymers, film was first dissolved in distilled water. Methanol was added to dissolve the drug without causing precipitation of polymers. From the above solution, $1 \mathrm{~mL}$ was placed in the donor compartment of the diffusion cell. The cellophane membrane was soaked overnight in SVF before the study. The receptor compartment was filled with SVF ( $\mathrm{pH} 4.2$ ). The temperature of the receptor compartment was maintained at $37 \pm 0.2^{\circ} \mathrm{C}$ and the stirring was maintained at $200 \mathrm{rpm}$ so that after diffusion, the drug is uniformly distributed in the receptor compartment throughout the study. At the specified time interval, $1.5 \mathrm{~mL}$ of the sample was withdrawn from the receptor compartment and fresh buffer solution of the same volume was added to it. The samples were then analyzed using UV-visible spectrophotometer and percentage drug diffusion was calculated..$^{[11]}$

\section{Scanning electron microscopy}

The surface morphology of the film was observed using a scanning electron microscope (Jeol JSM 5601 LV, Japan). The film sample was placed in the sample holder, and double side adhesive tape was used. The photomicrographs were at $100 \times$ and $550 \times$ magnification after gold plating. The surface morphology of the film forming excipient HPC and CT and films was observed using scanning electron microscope as surface morphology indicates uniformity of film and the absence of striations in the film. ${ }^{[8,10,15]}$

\section{Mucoadhesive strength}

The protocol for the animal study was approved by the Institutional Animals Ethics Committee with the protocol number IP/PCEU/MPH/14-1/009 dated January 10, 2014. The excised Wistar rat vaginal mucosa was washed with saline solution and kept in SVF prior to use. A square piece (surface area $1 \mathrm{~cm}^{2}$ ) of the mucosa was glued to an upper probe of the same size with the help of double sided adhesive tape. The vaginal mucosa was moistened using SVF. Mucosal membrane was kept in contact with the film for $2 \mathrm{~min}$ to allow the formation of an adhesive bond. An upper probe of the texture analyzer was moving at a speed of $0.1 \mathrm{~mm} / \mathrm{s}$. The force required to detach the film from the tissue surface was determined as mucoadhesive strength. ${ }^{[10,14]}$

\section{Antimicrobial activity and Lactobacillus inhibition}

Antifungal studies were performed for C.albicans in sabouraud's agar medium by the cup plate method. The cups cut in the inoculated solidified media were filled with different formulations using sterilized syringes. The marketed tablet (Candid $®-V 6$ tablet) was crushed into a powder and dissolved in $2 \mathrm{~mL}$ of sterilized water in a sterilized syringe. The optimized mucoadhesive film swelled in $2 \mathrm{~mL}$ of sterile water applied 
into the cups. The covered Petri plates were incubated at $22^{\circ} \mathrm{C}$ in the biological oxygen demand incubator for $48 \mathrm{~h}$. The zone of inhibition was measured at the end of 48 h. Lactobacillus is nonpathogenic bacteria normally present in the vagina to maintain its acidic $\mathrm{pH}$. The formulation should not adversely affect the flora of the human vagina. Lactobacillus inhibition was also studied using Lactobacillus acidophilus by the same procedure described previously. ${ }^{[10,16]}$

\section{RESULTS AND DISCUSSION}

\section{Drug-excipient compatibility study}

CT and various polymer mixtures showed the respective characteristic bands of CT at 1368, 1671, and 1136/cm. The results confirmed that there was no chemical interaction between drug and excipients. DSC thermogram of CT exhibiting an endothermic peak at $150.83^{\circ} \mathrm{C}$, corresponded to its melting point. Thermogram of CT and excipients physical mixture showed a peak at $147 \cdot 10^{\circ} \mathrm{C}$. Hence it could be concluded that drug and excipients were compatible.

\section{Preliminary trials}

Preliminary trials were conducted using sodium alginate and HPC as film forming polymer and PG, and PEG-400 were used as plasticizers in $20 \mathrm{~mL}$ of distilled water as solvent at $40^{\circ} \mathrm{C}$ using a hot air oven.

\section{Selection of casting surface}

The initial trials for optimizing casting surface were carried out using various concentrations of film forming agents like sodium alginate and HPC. HPC was selected because of its excellent film forming and quick disintegration property. Sodium alginate was selected as the film forming agent as it provides mucoadhesiveness along with film forming property. Solutions containing 1-3\% w/v sodium alginate and HPC alone were casted on both glass and plastic Petri dish and after drying films were evaluated for peelability. From the above results, it was concluded that films containing sodium alginate and HPC alone had better peelability using plastic as a casting surface as compared to the glass surface. Therefore, plastic as a casting surface was selected in further trials.

\section{Selection of film forming polymer}

The concentration of HPC varied from $1 \%$ to $5 \% \mathrm{w} / \mathrm{v}$ and evaluated for in vitro disintegration time, tensile strength, and folding endurance of the films. A batch containing $1 \% \mathrm{w} / \mathrm{v}$ HPC as well as sodium alginate alone was not peelable which might be due to the low amount of the polymer. The films formed in $2-5 \% \mathrm{HPC}$ as well as $2-3 \% \mathrm{w} / \mathrm{v}$ sodium alginate alone had a tensile strength below $352 \mathrm{~g} / \mathrm{mm}^{2}$. Hence, HPC and sodium alginate alone were not considered suitable for further trials. As HPC and sodium alginate alone could not provide desirable film properties, addition of plasticizers was tried in further batches. PEG-400 was added at a ratio of $0.2: 1$ and $0.4: 1$ of PEG-400: Polymer ratio. PEG 400 at 0.2:1 of plasticizer: HPC ratio could not form a film. As the amount of PEG-400 was increased to
0.4:1 (PEG-400: HPC ratio), the film was formed, but had a low tensile strength $\left(134.69 \pm 2.45 \mathrm{~g} / \mathrm{mm}^{2}\right)$. As PEG-400: HPC ratio was increased to $0.6: 1$, the film became too soft and difficult to handle. While at 0.2:1 ratio of PEG-400: Sodium alginate, the film had a tensile strength of $185.71 \pm 2.98$ and percentage elongation of $2.41 \pm 2.21$. As the ratio of PEG-400: Sodium alginate was increased to $0.4: 1,264.28 \pm 2.67$ tensile strength and $3.09 \pm 1.98 \%$ elongation was obtained. As the tensile strength was below $350 \mathrm{~g} / \mathrm{mm}^{2}$ and percentage elongation was below 5 , it was concluded that another plasticizer PG will be required for further trials. Films containing $2 \%$ and $3 \% \mathrm{w} / \mathrm{v}$ of sodium alginate at $0.2: 1$ and $0.4: 1$ ratio of PG:sodium alginate was prepared. Film containing $2 \%$ sodium alginate and 0.4 : 1 ratio of PG: Sodium alginate gave $382.34 \pm 2.88$ tensile strength and $5.41 \pm 2.66 \%$ elongation. Film containing 2\% HPC with 0.2:1 of PG: HPC produced $344.89 \pm 2.14 \mathrm{~g} / \mathrm{mm}^{2}$ tensile strength and $4.97 \pm 2.22 \%$ elongation. Film containing $2 \% \mathrm{HPC}$ with $0.4: 1 \mathrm{PG}$ : HPC had $505.10 \pm 2.36$ tensile strength and $5.78 \pm 2.89 \%$ elongation. From the above results, it can be concluded that $\mathrm{PG}$ at $0.4: 1$ gives better mechanical strength than PEG-400. Hence PG in the ratio of 0.4:1 was selected for further trials. Film containing HPC and sodium alginate at $2 \% \mathrm{w} / \mathrm{v}$ alone were prepared using $\mathrm{PG}$ at a ratio of 0.4:1. Film containing 2\% w/v HPC, 0.4:1 PG: Polymer showed in vitro disintegration time $18 \pm 0.67 \mathrm{~min}, 597.89 \pm 2.24 \mathrm{~g} / \mathrm{mm}^{2}$, $5.6 \pm 2.11 \%$ elongation. Film containing $2 \% \mathrm{w} / \mathrm{v}$ sodium alginate with 0.4:1 PG: Polymer had $20 \pm 0.57 \mathrm{~min}$ in vitro disintegration time, $769.35 \pm 2.56 \mathrm{~g} / \mathrm{mm}^{2}$ and $10.87 \pm 1.34 \%$ elongation. As both films containing HPC and sodium alginate were acceptable, further trials were taken by incorporating $\mathrm{CT}$ in these batches.

\section{Preparation of vaginal film containing clotrimazole}

Batches HS1 and HS2 were formulated by the preparation of solution containing a combination of $2 \% \mathrm{w} / \mathrm{v} \mathrm{HPC}, 2 \% \mathrm{w} / \mathrm{v}$ sodium alginate, $0.2: 1$ and $0.4: 1$ of PG: Polymer in $20 \mathrm{~mL}$ of distilled water, respectively. This was followed by the addition of $675 \mathrm{mg}$ CT to the above solution. Similarly, batches HS3 and HS4 were formulated by preparation of solution containing a combination of $2 \% \mathrm{w} / \mathrm{v}$ of HPC, $2 \% \mathrm{w} / \mathrm{v}$ of sodium alginate, 0.2:1 and 0.4:1 of PEG-400: Polymer in $20 \mathrm{~mL}$ of distilled water respectively. CT weighing $675 \mathrm{mg}$ was added to the polymer solution. The solution was poured on a plastic Petri dish to deliver $100 \mathrm{mg}$ of CT per $3 \mathrm{~cm} \times 3 \mathrm{~cm}$ film. When CT was incorporated into previously optimized blank films, the film was difficult to separate so trials were conducted using PG as plasticizers for efficient film separation. Even after adding plasticizer: Polymer in a ratio of $0.4: 1$, the film could not be separated from the plastic Petri dish. Hence, further trials were taken using Teflon as the casting surface. PG as plasticizer was used at a different ratio of $0.2: 1$ and $0.4: 1$ for further trials. It was observed that by using a Teflon Petri dish, drying time was significantly reduced from $18 \mathrm{~h}$ to $8 \mathrm{~h}$. Batch HS5 containing a combination of $2 \% \mathrm{w} / \mathrm{v}$ HPC, $2 \%$ w/v sodium alginate, $0.2: 1$ of PG: Polymer, formed a film with a low tensile strength of $438.77 \pm 2.56 \mathrm{~g} / \mathrm{mm}^{2}$ and higher in vitro disintegration time of $22 \pm 1.23 \mathrm{~min}$. Batch HS6 containing $2 \%$ w/v HPC, $2 \%$ w/v sodium alginate, 0.4:1 of PG:1 polymer had a higher tensile strength of $729.59 \pm 2.89 \mathrm{~g} / \mathrm{mm}^{2}$ and acceptable 
in vitro disintegration time of $20 \pm 2.34 \mathrm{~min}$. Batches HS7 and HS8 were formulated using the $0.2: 1$ and $0.4: 1$ ratio of PEG-400: Polymer. The film formed in batches HS7 and HS8 was very brittle and could not be completely removed. So, further trials were taken from different concentration of HPC and sodium alginate combination at 2, 3 and $4 \% \mathrm{w} / \mathrm{v}$ concentration as shown in Table 1 and batches HS9-HS12 were evaluated.

The results of batches HS9-HS12 shown in Table 1 indicate that batch HS 10 containing $1 \% \mathrm{w} / \mathrm{v}$ HPC and $1 \% \mathrm{w} / \mathrm{v}$ sodium alginate exhibits desired in vitro disintegration time of $10 \pm 0.57 \mathrm{~min}$, a high tensile strength of $884.67 \mathrm{~g} / \mathrm{mm}^{2}$, and a high swelling index of $75 \%$.

Comparative in vitro dissolution study of batches HS9-HS12 shown in Figure 1 indicates that as the concentration of sodium alginate increased, drug release was retarded and with the increase in concentration of HPC burst release was observed. However, batch HS10 containing $1 \% \mathrm{w} / \mathrm{v}$ of each HPC and sodium alginate showed the highest percentage drug release in $6 \mathrm{~h}$. In vitro diffusion study of batches HS9-HS12 was carried out as shown in Figure 2.

The results indicated that batch HS10 containing $2 \% \mathrm{w} / \mathrm{v}$ each of HPC and sodium alginate gave higher percentage of drug diffused $(31.65 \%)$ in $6 \mathrm{~h}$ as compared to other batches. Batch HS 10 also had desired mechanical properties; hence it was selected for further trials.

\section{Effect of different permeation enhancers}

It was observed that percentage drug diffusion for batch HS10 was $30 \%$ in 6 h. Various permeation enhancers, DMSO (5\%),

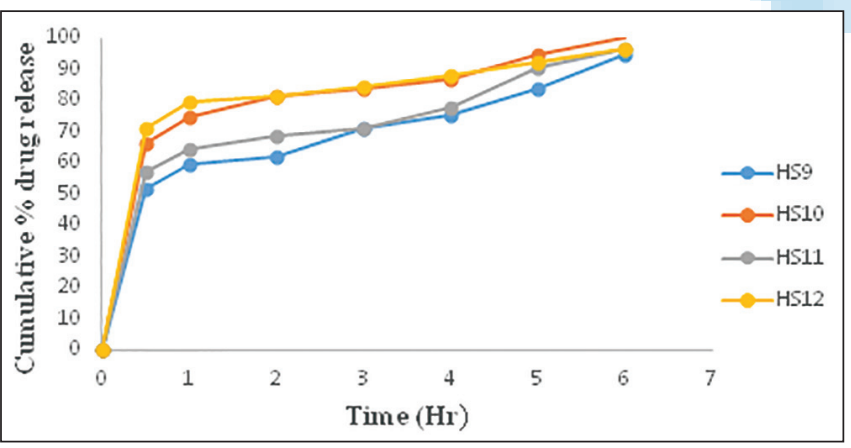

Figure 1: Comparative in vitro dissolution study of batch HS9-HS12
IPM $(2.5 \%)$ and triacetin (5\%) were used in batches HS13-HS15 to enhance drug diffusion as shown in Table 2.

It was observed that batch HS15 containing 2.5\% IPM possessed $186 \pm 2.88 \mu \mathrm{m}$ thickness, whereas batch HS14 containing $5 \%$ triacetin possessed $356 \pm 2.54 \mu \mathrm{m}$ thickness. It can also be correlated that as the thickness of film increases, in vitro disintegration time also increases. The tensile strength, elastic modulus, drug content and folding endurance of batches HS13-HS15 were acceptable.

Figure 3 indicates that batch HS15 containing $2.5 \% \mathrm{w} / \mathrm{v}$ of IPM and batch HS13 containing 5\% w/v of DMSO showed an almost similar diffusion profile. Since the concentration of DMSO was above the acceptable range for residual solvents as per ICH guidelines, further trials were taken using IPM as the permeation enhancer.

\section{Factorial design}

To systematically study the effect of two independent variables, that is, concentration of the polymer $\left(\mathrm{X}_{1}\right)$ and the amount of permeation enhancer $\left(\mathrm{X}_{2}\right)$ on the characteristics of the films, that is, responses in vitro diffusion study, in vitro disintegration time, and tensile strength a $3^{2}$ full factorial design was applied. A statistical model incorporating interactive and polynomial terms was used to evaluate the response using the following equation:

$\mathrm{Y}=\mathrm{b}_{0}+\mathrm{b}_{1} \mathrm{X}_{1}+\mathrm{b}_{2} \mathrm{X}_{2}+\mathrm{b}_{12} \mathrm{X}_{1} \mathrm{X}_{2}+\mathrm{b}_{11} \mathrm{X}_{1}^{2}+\mathrm{b}_{22} \mathrm{X}_{2}^{2}$

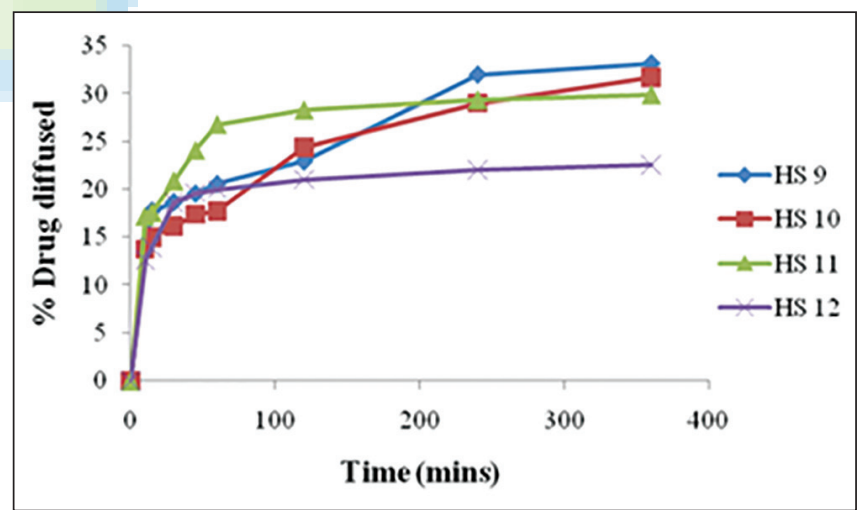

Figure 2: Comparative in vitro diffusion study of batch HS9-HS12

\begin{tabular}{|c|c|c|c|c|}
\hline Batch number/composition & HS9 & HS10 & HS11 & HS12 \\
\hline $\mathrm{HPC}(\% \mathrm{w} / \mathrm{v})$ & 2 & 1 & 2 & 1 \\
\hline Sodium alginate (\%w/v) & 2 & 1 & 1 & 2 \\
\hline PG:Polymer ratio & \multicolumn{4}{|c|}{$0.4: 1$} \\
\hline Thickness ( $\mu \mathrm{m})$ & $290 \pm 1.67$ & $136 \pm 1.98$ & $196 \pm 1.74$ & $310 \pm 1.88$ \\
\hline In vitro $\mathrm{DT}^{*}(\mathrm{~min})$ & $20 \pm 0.54$ & $10 \pm 0.57$ & $25 \pm 0.67$ & $15 \pm 0.78$ \\
\hline Tensile strength $\left(\mathrm{g} / \mathrm{mm}^{2}\right)$ & $628.57 \pm 2.65$ & $884.69 \pm 2.65$ & $405.10 \pm 2.75$ & $525.51 \pm 2.88$ \\
\hline Percentage drug content & $97.34 \pm 2.13$ & $98.45 \pm 2.09$ & $94.03 \pm 2.54$ & $97.34 \pm 2.76$ \\
\hline Elastic modulus & $1249 \pm 1.12$ & $2364 \pm 1.65$ & $2049 \pm 1.87$ & $802 \pm 1.98$ \\
\hline Folding endurance & $79 \pm 2.54$ & $86 \pm 2.23$ & $65 \pm 2.87$ & $60 \pm 2.66$ \\
\hline Percentage swelling index & $70 \pm 0.76$ & $75 \pm 0.54$ & $60 \pm 0.69$ & $80 \pm 0.54$ \\
\hline
\end{tabular}

*In vitro disintegration time. HPC: Hydroxypropyl cellulose, PG: Propylene glycol 
where $\mathrm{Y}$ is the dependent variable, $\mathrm{b}_{0}$ is the arithmetic mean response of the nine runs, and $\mathrm{b}_{\mathrm{i}}$ is the estimated coefficient for the factor $\mathrm{X}_{\mathrm{i}}$. The main effects $\left(\mathrm{X}_{1}\right.$ and $\left.\mathrm{X}_{2}\right)$ represent the average result of changing one factor at a time from its low to high value. The interaction terms $\left(\mathrm{X}_{1} \mathrm{X}_{2}\right)$ show how the response changes when two factors are simultaneously changed. The polynomial terms $\left(\mathrm{X}_{1}^{2}\right.$ and $\left.\mathrm{X}_{2}^{2}\right)$ are also included to investigate nonlinearity in developed formulation. The coded values used in the design is mentioned in Table 3.

Batches F1-F9 were formulated to study the effect of combination of HPC and sodium alginate and concentration of IPM on in vitro diffusion, in vitro disintegration time and tensile strength as shown in Table 4 . A desired range of percentage diffusion was found between $60 \%$ and $80 \%$, tensile strength between 450 and $510 \mathrm{~g} / \mathrm{mm}^{2}$ and in vitro disintegration time, 10-20 $\mathrm{min}$.

\begin{tabular}{|c|c|c|c|}
\hline $\begin{array}{l}\text { Batch numberl } \\
\text { compositiion }\end{array}$ & HS13 & HS14 & HS15 \\
\hline $\mathrm{HPC}(\% \mathrm{w} / \mathrm{v})$ & & 1 & \\
\hline Sodium alginate $(\% w / v)$ & & 1 & \\
\hline DMSO (\%w/v) & 5 & - & - \\
\hline Triacetin (\%w/v) & - & 5 & - \\
\hline IPM (\%w/v) & - & - & 2.5 \\
\hline PG:Polymer ratio & & $0.4: 1$ & \\
\hline Thickness $(\mu \mathrm{m})$ & $220 \pm 2.65$ & $356 \pm 2.54$ & $186 \pm 2.88$ \\
\hline In vitro $\mathrm{DT}^{*}(\min )$ & $20 \pm 0.76$ & $25 \pm 0.76$ & $18 \pm 0.57$ \\
\hline Tensile strength $\left(\mathrm{g} / \mathrm{mm}^{2}\right)$ & $462.22 \pm 2.76$ & $234.56 \pm 2.47$ & $512.45 \pm 2.45$ \\
\hline Percentage drug content & $98.35 \pm 2.18$ & $98.65 \pm 2.87$ & $97.03 \pm 2.17$ \\
\hline Elastic modulus & $1646 \pm 2.53$ & $2464 \pm 2.67$ & $2549 \pm 2.32$ \\
\hline Folding endurance & $75 \pm 2.26$ & $51 \pm 2.67$ & $78 \pm 2.27$ \\
\hline
\end{tabular}

*In vitro disintegration time. HPC: Hydroxypropyl cellulose, PG: Propylene glycol, DMSO: Dimethyl sulfoxide, IPM: Isopropyl myristate

\section{Table 3: Coded values of $3^{2}$ full factorial design}

\begin{tabular}{lcc}
\hline Concentration & Coded value & Actual value (\%) \\
\hline Concentration of polymer $\left(\mathrm{X}_{1}\right)$ & $\square 1$ & 1 \\
HPC:Sodium alginate $(50: 50)$ & 0 & 2 \\
& +1 & 3 \\
Permeation enhancer $\left(\mathrm{X}_{2}\right)$ & $\square 1$ & 2 \\
& 0 & 4 \\
& +1 & 6 \\
\hline
\end{tabular}

HPC: Hydroxypropyl cellulose

\section{Percentage diffusion}

The full model equation for percentage diffusion was generated using Design Expert ${ }^{\circledR}$ software version 8 (Statease) as shown in the following equation:

$\mathrm{Y}=56.684+7.878 \mathrm{X}_{1}+2.318 \mathrm{X}_{2}-4.846 \mathrm{X}_{1} \mathrm{X}_{2}+$ $5.728 \mathrm{X}_{1}^{2}+2.278 \mathrm{X}_{2}^{2}$

From the response surface plot and contour plots as shown in Figure 4 and polynomial equation generated, it is clearly evident that as the concentration of permeation enhancer increases, the percentage diffusion increases. Similarly, as the concentration of the polymer increases percentage diffusion of the drug increases which can be explained by the fact that sodium alginate at higher concentration acts as a disintegrant. As the disintegration time will decrease, there may be an increase in drug diffusion. Interestingly, the magnitude of the concentration of polymer is higher than permeation enhancer. The role of polymer HPC and sodium alginate needs to be explored for percentage diffusion. As the polynomial terms $\left(\mathrm{X}^{2}\right.$ and $\left.\mathrm{X}_{1} \mathrm{X}_{2}\right)$ have $P>0.05$, reduced model of the equation was generated.

The reduced model was generated for percentage drug diffusion was calculated on the basis $P$ value as shown in equation:

$Y=56.684+7.878 X_{1}+2.318 X_{2}-4.848 X_{1} X_{2}$

From the reduced model equation (6), it can be concluded that the concentration of permeation enhancer has more effect on percentage diffusion than the concentration of the polymer.

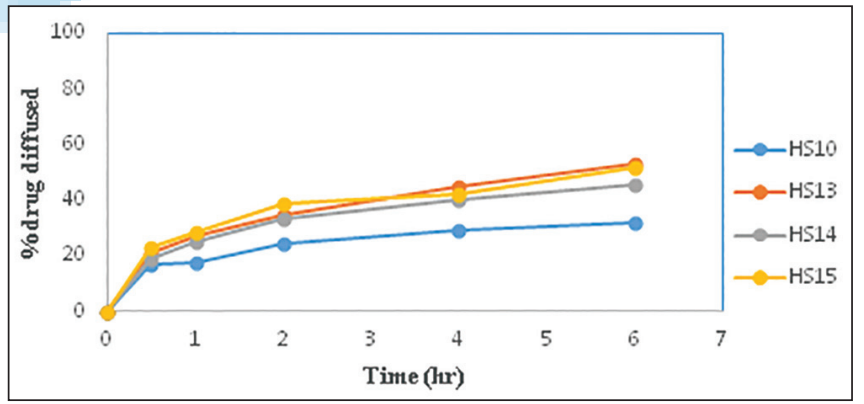

Figure 3: Comparative in vitro diffusion study of batch HS10 with batch HS13-HS15

Table 4: $3^{2}$ full factorial design

\begin{tabular}{|c|c|c|c|c|c|}
\hline \multirow[t]{2}{*}{ Batch code } & \multicolumn{2}{|c|}{ Variable level in coded form } & \multirow[t]{2}{*}{ Percentage diffusion } & \multirow[t]{2}{*}{ Tensile strength $\left(\mathrm{g} / \mathrm{mm}^{2}\right)$} & \multirow[t]{2}{*}{ In vitro $\mathrm{DT}^{*}(\mathrm{~min})$} \\
\hline & $\mathrm{X}_{1}$ & $\mathrm{X}_{2}$ & & & \\
\hline F1 & $\square 1$ & $\square 1$ & 70.45 & $332.5 \pm 2.52$ & $12 \pm 0.51$ \\
\hline F2 & 0 & $\square 1$ & 60.29 & $302.13 \pm 2.88$ & $16 \pm 0.55$ \\
\hline F3 & 1 & $\square 1$ & 77.09 & $502.1 \pm 2.21$ & $18 \pm 0.62$ \\
\hline F4 & $\square 1$ & 0 & 58.5 & $183.41 \pm 1.98$ & $13 \pm 0.67$ \\
\hline F5 & 0 & 0 & 53.21 & $258.06 \pm 2.45$ & $16 \pm 0.56$ \\
\hline F6 & 1 & 0 & 63.69 & $417.8 \pm 2.61$ & $19 \pm 0.44$ \\
\hline F7 & $\square 1$ & 1 & 50.5 & $154.34 \pm 2.99$ & $14 \pm 0.68$ \\
\hline F8 & 0 & 1 & 51.02 & $166.25 \pm 3.11$ & $15 \pm 0.78$ \\
\hline F9 & 1 & 1 & 58.27 & $402.8 \pm 2.14$ & $20 \pm 0.83$ \\
\hline
\end{tabular}

*In vitro disintegration time 


\section{Tensile strength}

The full model equation for tensile strength was generated as shown in equation (7):

$\mathrm{Y}=226.416+108.742 \mathrm{X}_{1}-68.89 \mathrm{X}_{2}+19.715 \mathrm{X}_{1} \mathrm{X}_{2}+90.012 \mathrm{X}_{1}^{2}$ $+23.597 \mathrm{X}_{2}^{2}$

As the polynomial terms $\left(\mathrm{X}_{1}^{2}\right.$ and $\left.\mathrm{X}_{1} \mathrm{X}_{2}\right)$ have $P<0.05$, reduced model of the equation was generated as shown in equation (8). From the above reduced model equation, it can be concluded that the concentration of polymer exhibits a significant effect on tensile strength than the concentration of the permeation enhancer.

$Y=226.416+108.742 X_{1}-68.89 X_{2}+90.012 X_{1}^{2}$

From the response surface plot and contour plots as shown in Figure 5 and polynomial equation generated, it can be concluded that as the concentration of polymer increases, tensile strength increases. As the concentration of permeation enhancer increases, tensile strength decreases. The magnitude of polymer is higher than the concentration of permeation enhancer. Thus, concentration of polymer has a more significant effect on tensile strength.

\section{In vitro disintegration time}

The full model equation for in vitro disintegration time was generated as shown in the following equation (9):

$\mathrm{Y}=15.889+3 \mathrm{X}_{1}+0.5 \mathrm{X}_{2}$

From the response surface plot and contour plots as shown in Figure 6 and polynomial equation generated, we can conclude that as the concentration of the polymer increases in vitro disintegration time also increases. However, as the concentration of permeation enhancer increases, there is no significant difference in the in vitro disintegration time. Equation (9) shows that the magnitude of the concentration of polymer is higher than the concentration of permeation enhancer. Thus, concentration of the polymer has a more significant effect on in vitro disintegration time. From the results obtained, it was found that $2 \% \mathrm{w} / \mathrm{v}$ IPM as a permeation enhancer in batches F1-F3 exhibited in vitro disintegration time within the desired range and there was an increase in tensile strength as the concentration of polymer increased. Percentage drug diffusion was highest in batch F3 containing $3 \%$ combination of polymer and $2 \%$ of IPM as permeation enhancer. Batches F4-F9 containing $4 \% \mathrm{w} / \mathrm{v}$ and $6 \% \mathrm{w} / \mathrm{v}$ of IPM as a permeation enhancer showed significant decrease in percentage drug diffusion and tensile strength compared to the batches containing $2 \% \mathrm{w} / \mathrm{v}$ of IPM as the permeation enhancer. There was an increase in in vitro disintegration time, but it was within acceptable range $(20 \mathrm{~min})$. Therefore batch $\mathrm{F} 3$ containing combination of $3 \% \mathrm{w} / \mathrm{v}$ of the polymer and $2 \%$ w/v of IPM had $77.09 \%$ drug diffusion, $502.1 \mathrm{~g} / \mathrm{mm}^{2}$ tensile strength and $18 \mathrm{~min}$ in vitro disintegration time. This batch was selected as an optimized batch from the factorial design study.

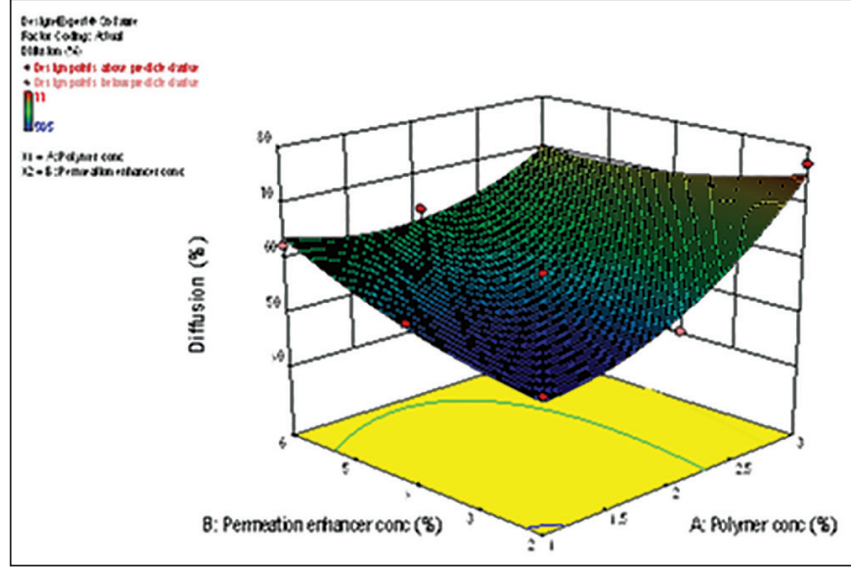

Figure 4: Response surface plot for \%diffusion

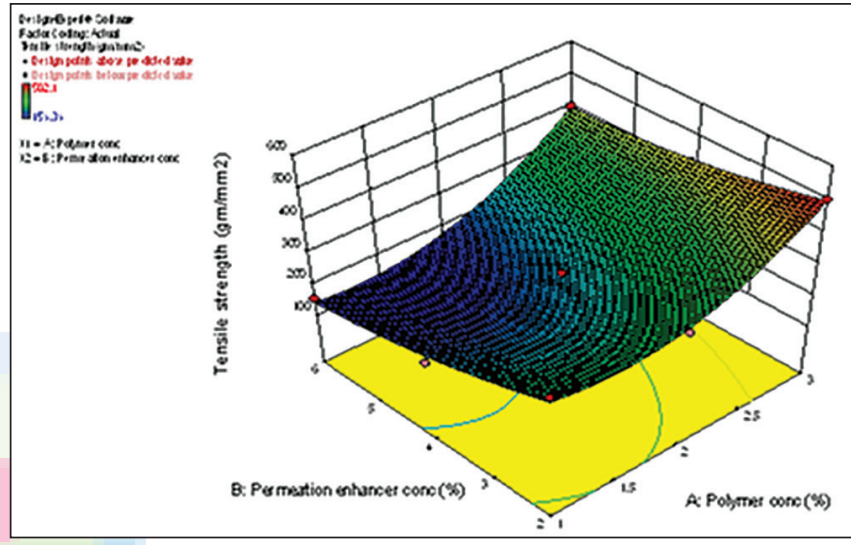

Figure 5: Response surface plot for tensile strength

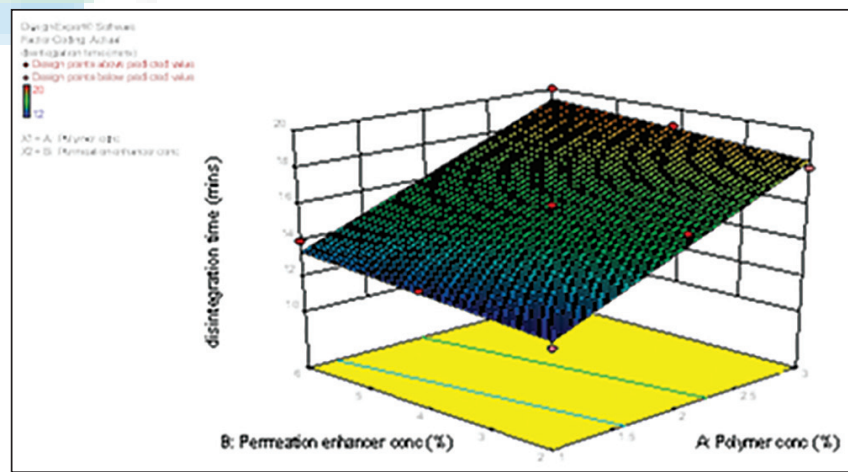

Figure 6: Response surface plot for in vitro disintegration time

Two check point batches F10 and F11 were taken to validate the model as shown in Table 5 .

From the check point batches F10 and F11, it can be concluded that observed values are similar to the expected value and thus generated mathematical model is valid.

\section{Swelling study}

The swelling capability of polymer is crucial for its mucoadhesiveness. Swelling study of batches F1-F9 for the period of $6 \mathrm{~h}$ is shown in Figure 7. 
From the result, it can be observed that as the concentration of combination of polymer increased, percentage swelling index also increased. With increasing concentration of the permeation enhancer there was a slight decrease in the percentage swelling index. Highest percentage swelling index was observed in batch $\mathrm{F} 3$ containing $3 \%$ of combination of polymers and $2 \% \mathrm{w} / \mathrm{v}$ of permeation enhancer.

Mucoadhesion and retention in simulated vaginal environment

Mucoadhesion is a very important aspect for maintaining high drug concentration at the site of administration and prevention of expulsion of formulation. By maintaining effective drug concentration for longer time, successful eradication of infectious agent can be achieved. The mucoadhesive strength of the film increased with increased content of HPC up to a certain extent and then decreased. As the concentration of PG in film increased, bioadhesive strengths of film decreased. This finding suggests that adhesion will improve with the extent of hydration until an optimum point where over hydration leads to a decrease in adhesive force due to disentanglement at the polymer/tissue interface. Ex vivo mucoadhesive strength of optimized batch was done on rat vaginal mucosa. The force required to detach the optimized film from tissue was found to be $0.705 \mathrm{~N}$.

\section{Scanning electron microscopy of optimized batch}

The surface morphology of the film was assessed using scanning electron microscopy (SEM).

Figure $8 \mathrm{a}-\mathrm{c}$ shows SEM of CT at $550 \times$, HPC at $600 \times$ and SEM of vaginal film at $550 \times$ magnification. It showed that there was a uniform distribution of drug throughout the film. There was also no

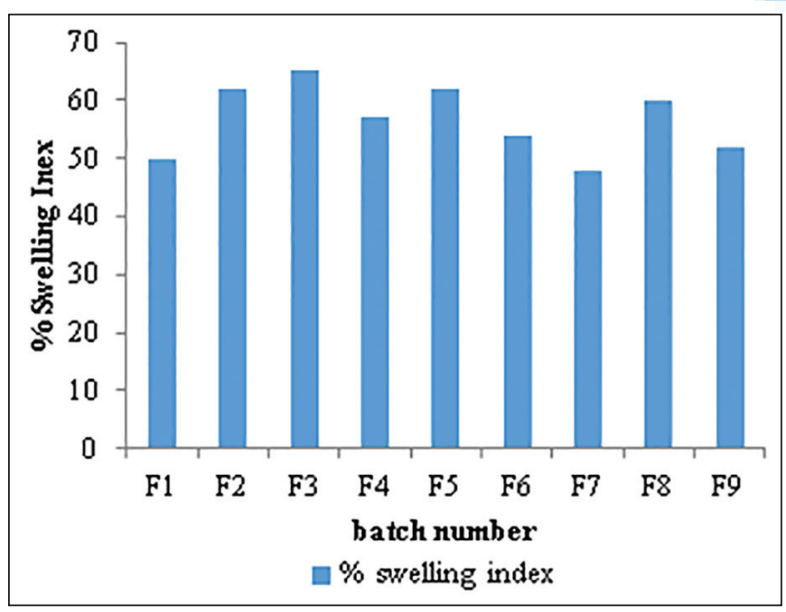

Figure 7: Comparative percentage swelling index of batch F1-F9 agglomeration of particles. The overall image of SEM showed that there were no striation or fractures in the film, which indicated that the film formed will not have any problem in mechanical property. Thus, it could be concluded that the developed mucoadhesive vaginal film containing a uniform particle distribution of CT.

In vitro antifungal studies and lactobacillus inhibition In vitro antifungal studies of prepared mucoadhesive vaginal film was compared with the marketed product, Candid-V6 ${ }^{\circledR}$ tablet

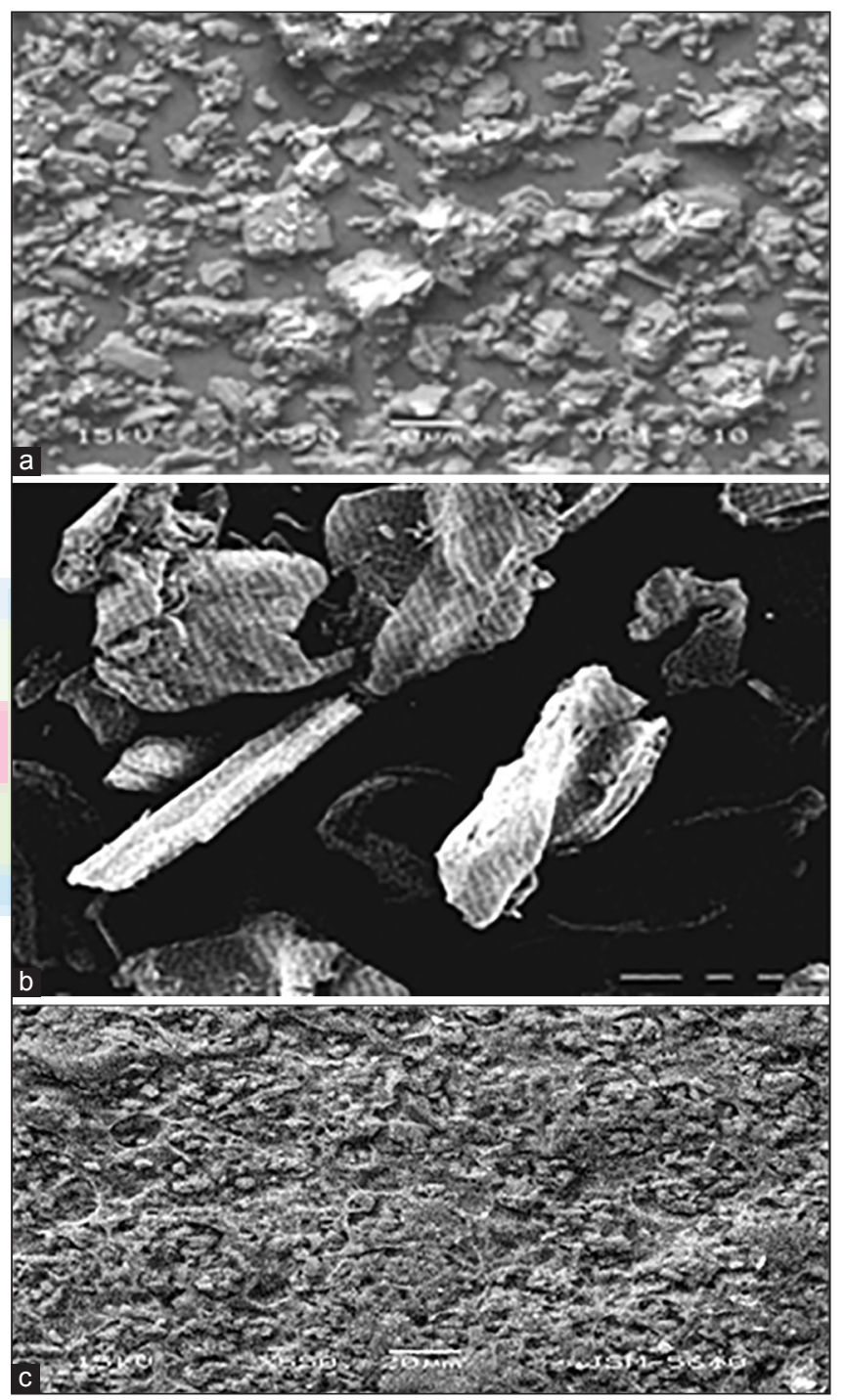

Figure 8: (a) Scanning electron microscopy of clotrimazole at 550x magnification. (b) Scanning electron microscopy of hydroxypropyl cellulose at $600 \times$ magnification. (c) Scanning electron microscopy of vaginal film at $550 \times$ magnification

Table 5: Check point batches for validation of batches

\begin{tabular}{|c|c|c|c|c|c|c|c|c|}
\hline \multirow{2}{*}{$\begin{array}{l}\text { Batch } \\
\text { code }\end{array}$} & \multicolumn{2}{|c|}{ Composition } & \multicolumn{3}{|c|}{ Expected value } & \multicolumn{3}{|c|}{ Observed value } \\
\hline & $\begin{array}{l}\text { Polymer } \\
(\% w / v)\end{array}$ & Plasticizer & $\begin{array}{l}\text { Percentage drug } \\
\text { diffused }\end{array}$ & $\begin{array}{l}\text { Tensile strength } \\
\left(\mathrm{g} / \mathrm{mm}^{2}\right)\end{array}$ & $\begin{array}{l}\text { In vitro } \mathrm{DT}^{*} \\
(\min )\end{array}$ & $\begin{array}{l}\text { Percentage } \\
\text { drug diffused }\end{array}$ & $\begin{array}{l}\text { Tensile strength } \\
\left(\mathrm{g} / \mathrm{mm}^{2}\right)\end{array}$ & $\begin{array}{l}\text { In vitro } D^{*} T^{*} \\
(\mathrm{~min})\end{array}$ \\
\hline F10 & 3.19 & 5.00 & 73.14 & 468.79 & 19.73 & 71.36 & 465.34 & 19.10 \\
\hline F11 & 3.07 & 2.52 & 75.09 & 494.70 & 18.73 & 76.90 & 491.43 & 18.67 \\
\hline
\end{tabular}

*/n vitro disintegration time 
against $C$. albicans. The zone of inhibition of the optimized film F3 was $24 \mathrm{~mm}$ comparable with the zone of inhibition of marketed product having value $23 \mathrm{~mm}$. Lactobacillus inhibition study showed that the optimized film $(8 \mathrm{~mm})$ as well as a marketed product $(10 \mathrm{~mm})$ did not inhibit the growth of Lactobacillus. This indicates the enhanced antifungal activity for the developed film.

\section{Comparative in vitro dissolution studies of optimized} film with marketed product, Candid- ${ }^{\circ}{ }^{\odot}$ tablet

The optimized film showed $70 \%$ drug release in $1 \mathrm{~h}$ and $83 \%$ drug release in $6 \mathrm{~h}$ while marketed product showed $14 \%$ drug release in $1 \mathrm{~h}$ and $41 \%$ drug release in $6 \mathrm{~h}$. It can be concluded that the prepared mucoadhesive vaginal film showed a higher drug release profile than the marketed product.

\section{Percentage swelling index of optimized film with a} marketed product, Candid- $\mathbf{V}^{\circ}$ tablet

Percentage swelling index of Candid-V6 ${ }^{\circledR}$ vaginal tablet was found nearly similar (70\%) compared to an optimized batch F3 (60\%).

\section{CONCLUSION}

Mucoadhesive vaginal film of CT was formulated and evaluated for the treatment of VC. Film forming polymers, HPC and sodium alginate were utilized in the study. PG was selected as plasticizer. Among various permeation enhancers used, IPM was selected. The mucoadhesive vaginal films were evaluated for percentage elongation, tensile strength, folding endurance, drug content, in vitro disintegration time, in vitro dissolution study, swelling index, bioadhesive strength, and diffusion study. The formulation was optimized by using $3^{2}$ full factorial design to study the effect of two independent variables, amount of polymers and concentration of permeation enhancer in optimization of mucoadhesive vaginal film on in vitro disintegration time, percentage drug diffusion and tensile strength. The concentration of permeation enhancer had a more significant effect on diffusion. In vitro disintegration time increased with increase in concentration of polymer and increase in the concentration of permeation enhancer did not cause significant change in in vitro disintegration time. As the concentration of polymer was increased, tensile strength increased and as the concentration of permeation enhancer increased tensile strength decreased. The magnitude of polymer was higher than the concentration of permeation enhancer. Thus, concentration of polymer had more significant effect on tensile strength. Optimized batch $\mathrm{F} 3$ possessed in vitro disintegration time $18 \mathrm{~min}$, drug content $99.83 \%$ and tensile strength $502.1 \mathrm{~g} / \mathrm{mm}^{2}$ and $77 \%$ in vitro drug diffusion in 6 h. In vitro Lactobacillus inhibition and in vitro antifungal activity of optimized batch showed inhibitory effect against $C$. albicans and no effect on the growth of Lactobacillus. Overall results obtained in the study suggest that mucoadhesive vaginal film possessed desirable aesthetic properties and making it convenient for the effective treatment of VC.

\section{Financial support and sponsorship}

Nil.

\section{Conflicts of interest}

There are no conflicts of interest.

\section{REFERENCES}

1. Hussain A, Ahsan F. The vagina as a route for systemic drug delivery. J Control Release 2005;103:301-13.

2. Valenta $\mathrm{C}$. The use of mucoadhesive polymers in vaginal delivery. Adv Drug Deliv Rev 2005;57:1692-712.

3. Garg S, Goldman D, Krumme M, Rohan LC, Smoot S, Friend DR. Advances in development, scale-up and manufacturing of microbicide gels, films, and tablets. Antiviral Res 2010;88(Suppl 1):S19-29.

4. Malcolm R, McCullagh S, Morrow R, Woolfson A. Vagina and uterus as drug - Absorbing organs. In: Touitou E, Barry BW, editors. Enhancement in Drug Delivery. Florida: CRC Press; 2007. p. 395-430.

5. Choudhury A, Das S, Kar M. A review on novelty and potentiality of vaginal drug delivery. Int J PharmTech Res 2011;3:1033-44.

6. Maryadele JO, Heckelman P, Kristin P, Linda C, editors. The Merck Index, An Encylopedia of Chemicals, Drugs and Biologicals. $15^{\text {th }}$ ed. Cambridge: Royal Society of Chemistry; 2013. p. 432.

7. Florey K, editor. Analytical Profiles of Drug Substances. $1^{\text {st }}$ ed., Vol. 11. New York: Academic Press; 2005. p. 225-53.

8. Zhang W, Parniak MA, Sarafianos SG, Cost MR, Rohan LC. Development of a vaginal delivery film containing EFdA, a novel anti-HIV nucleoside reverse transcriptase inhibitor. Int J Pharm 2014;461:203-13.

9. Yoo JW, Dharmala K, Lee CH. The physicodynamic properties of mucoadhesive polymeric films developed as female controlled drug delivery system. Int J Pharm 2006;309:139-45.

10. Dobaria NB, Badhan AC, Mashru RC. A novel itraconazole bioadhesive film for vaginal delivery: Design, optimization, and physicodynamic characterization. AAPS PharmSciTech 2009;10:951-9.

11. Kumar L, Reddy MS, Shirodkar RK, Pai GK, Krishna VT, Verma R. Preparation and characterisation of fluconazole vaginal films for the treatment of vaginal candidiasis. Indian $\mathrm{J}$ Pharm Sci 2013;75:585-90.

12. Kawarkhe S, Poddar SS. Design of mucoadhesive vaginal metronidazole films. Acta Pharm Sciencia 2010;52:181-9.

13. Akil A, Parniak MA, Dezzuitti CS, Moncla BJ, Cost MR, Li M, et al. Development and characterization of a vaginal film containing dapivirine, a non- nucleoside reverse transcriptase inhibitor (NNRTI), for prevention of HIV-1 sexual transmission. Drug DelivTransI Res 2011;1:209-22.

14. Bhat R, Sudeendra HU, Gupta RK, Shivkumar HG. Development and characterization of bioadhesive vaginal films of clotrimazole for vaginal candidiasis. Acta Pharm Sciencia 2010;52:417-26.

15. Real DA, Martinez MV, Frattini A, Soazo M, Luque AG, Biasoli $\mathrm{MS}$, et al. Design, characterization, and in vitro evaluation of antifungal polymeric films. AAPS PharmSciTech 2013;14:64-73.

16. Ham AS, Rohan LC, Boczar A, Yang L, Buckheit KW, Buckheit RW Jr. Vaginal film drug delivery of the pyrimidinedione IQP-0528 for the prevention of HIV infection. Pharm Res 2012;29:1897-907. 